University of Nebraska - Lincoln

DigitalCommons@University of Nebraska - Lincoln

$1-2012$

\title{
Development of a framework based on an ecosystem services approach for deriving specific protection goals for environmental risk assessment of pesticides
}

\author{
Karin M. Nienstedt \\ European Food Safety Authority, Parma, Italy \\ Theo C. M. Brock \\ Wageningen University and Research Centre, The Netherlands \\ Joke van Wensem \\ Soil Protection Technical Committee, The Netherlands \\ Mark Montforts \\ National Institute for Public Health and the Environment, The Netherlands \\ Andy Hart \\ Food and Environment Research Agency, Sand Hutton, York, UK
}

See next page for additional authors
Follow this and additional works at: https://digitalcommons.unl.edu/biosciforbes

Part of the Pharmacology, Toxicology and Environmental Health Commons

Nienstedt, Karin M.; Brock, Theo C. M.; van Wensem, Joke; Montforts, Mark; Hart, Andy; Aagaard, Alf; Alix, Anne; Boesten, Joes; Bopp, Stephanie K.; Brown, Colin; Capri, Ettore; Forbes, Valery E.; Köpp, Herbert; Liess, Matthias; Luttik, Robert; Maltby, Lorraine; Sousa, José P.; Streissl, Franz; and Hardy, Anthony R., "Development of a framework based on an ecosystem services approach for deriving specific protection goals for environmental risk assessment of pesticides" (2012). Valery Forbes Publications. 37.

https://digitalcommons.unl.edu/biosciforbes/37

This Article is brought to you for free and open access by the Papers in the Biological Sciences at DigitalCommons@University of Nebraska - Lincoln. It has been accepted for inclusion in Valery Forbes Publications by an authorized administrator of DigitalCommons@University of Nebraska - Lincoln. 


\section{Authors}

Karin M. Nienstedt, Theo C. M. Brock, Joke van Wensem, Mark Montforts, Andy Hart, Alf Aagaard, Anne Alix, Joes Boesten, Stephanie K. Bopp, Colin Brown, Ettore Capri, Valery E. Forbes, Herbert Köpp, Matthias Liess, Robert Luttik, Lorraine Maltby, José P. Sousa, Franz Streissl, and Anthony R. Hardy 


\title{
Development of a framework based on an ecosystem services approach for deriving specific protection goals for environmental risk assessment of pesticides
}

\author{
Karin M. Nienstedt, ${ }^{1, *}$ Theo C. M. Brock, ${ }^{2}$ Joke van Wensem, ${ }^{3}$ Mark Montforts, ${ }^{4}$ Andy Hart,${ }^{5}$ Alf Aagaard,${ }^{5, \dagger}$ \\ Anne Alix, ${ }^{6}$ Jos Boesten, ${ }^{2}$ Stephanie K. Bopp, ${ }^{1}$ Colin Brown, ${ }^{7}$ Ettore Capri, ${ }^{8}$ Valery Forbes,${ }^{9}$, Herbert Köpp, ${ }^{10}$ \\ Matthias Liess, ${ }^{11}$ Robert Luttik, ${ }^{4}$ Lorraine Maltby, ${ }^{12}$ José P. Sousa, ${ }^{13}$ Franz Streissl, ${ }^{1}$ Anthony R. Hardy ${ }^{14}$ \\ 1. European Food Safety Authority (EFSA), Largo N. Palli 5/A, 43121 Parma, Italy \\ 2. Alterra, Wageningen University and Research Centre, Droevendaalsesteeg 3a, 6708PB Wageningen, The Netherlands \\ 3. Soil Protection Technical Committee, P.O. Box 30947, The Hague, The Netherlands \\ 4. National Institute for Public Health and the Environment (RIVM), P.O. Box 1, 3720 BA Bilthoven, The Netherlands \\ 5. Food and Environment Research Agency, Sand Hutton, York, YO41 1LZ, UK \\ 6. General Directorate on Food, Ministry of Food, Agriculture, Fisheries and Rural Affairs, 251 rue de Vaugirard, 75732 Paris Cedex, France \\ 7. Environment Department, University of York, Heslington, York, YO10 5DD, UK \\ 8. Istituto di Chimica Agraria ed Ambientale, Università Cattolica del Sacro Cuore, Via Emilia Parmense 86, 29100 Piacenza, Italy \\ 9. Department of Environmental, Social and Spatial Change, Roskilde University, P.O. Box 260, 4000 Roskilde, Denmark \\ 10. Federal Office of Consumer Protection and Food Safety (BVL), Bundesallee 50, 38116 Braunschweig, Germany \\ 11. UFZ, Helmholtz Centre for Environmental Research, Dept. System Ecotoxicology, Permoser Str. 15, 04318 Leipzig, Germany \\ 12. Department of Animal and Plant Sciences, The University Sheffield, Western Bank, Sheffield, S10 2TN, UK \\ 13. IMAR-CMA, Department of Life Sciences, University of Coimbra, 3001-401 Coimbra, Portugal \\ 14. Bishops Cottage, 2 Church Lane, Bishopthorpe, York, YO23 2QG, UK \\ Corresponding author — S. K. Bopp, European Food Safety Authority, PPR Unit, Largo N. Palli 5/A, 43121 Parma (PR), Italy; tel 390521036545 , fax 39 \\ 05210360545 ,email stephanie.bopp@efsa.europa.eu \\ * Present address for K. M. Nienstedt — European Commission, Health and Consumers Directorate-General, Rue Breydel 4, 1040 Brussels, Belgium. \\ $\uparrow$ Present address for A. Aagaard - Pesticides \& Gen Technology, Danish Environmental Protection Agency, Strandgade 29, 1401 Copenhagen K, Denmark. \\ $\$$ Present address for V. Forbes — School of Biological Sciences, University of Nebraska-Lincoln, Lincoln, NE, 68588, USA.
}

\begin{abstract}
General protection goals for the environmental risk assessment (ERA) of plant protection products are stated in European legislation but specific protection goals (SPGs) are often not precisely defined. These are however crucial for designing appropriate risk assessment schemes. The process followed by the Panel on Plant Protection Products and their Residues (PPR) of the European Food Safety Authority (EFSA) as well as examples of resulting SPGs obtained so far for environmental risk assessment (ERA) of pesticides is presented. The ecosystem services approach was used as an overarching concept for the development of SPGs, which will likely facilitate communication with stakeholders in general and risk managers in particular. It is proposed to develop SPG options for 7 key drivers for ecosystem services (microbes, algae, non target plants (aquatic and terrestrial), aquatic invertebrates, terrestrial non target arthropods including honeybees, terrestrial non-arthropod invertebrates, and vertebrates), covering the ecosystem services that could potentially be affected by the use of pesticides. These SPGs need to be defined in 6 dimensions: biological entity, attribute, magnitude, temporal and geographical scale of the effect, and the degree of certainty that the specified level of effect will not be exceeded. In general, to ensure ecosystem services, taxa representative for the key drivers identified need to be protected at the population level. However, for some vertebrates and species that have a protection status in legislation, protection may be at the individual level. To protect the provisioning and supporting services provided by microbes it may be sufficient to protect them at the functional group level. To protect biodiversity impacts need to be assessed at least at the scale of the watershed/ landscape.
\end{abstract}

Keywords: protection goals, ecosystem services, environmental risk assessment, pesticides, guidance documents, ecotoxicology

Abbreviations: ERA, Environmental Risk Assessment; ERC, Ecotoxicologically Relevant Concentration; EFSA, European Food Safety Authority; ES, Ecosystem Service; GD, Guidance Document; MEA, Millennium Ecosystem Assessment; PPR EFSA, Panel on Plant Protection Products and their Residues; SPG, Specific Protection Goal 


\section{Introduction}

In 2009, the Panel on Plant Protection Products and their Residues (PPR) of the European Food Safety Authority (EFSA) was asked to revise the Guidance Documents (GDs) for Aquatic Ecotoxicology and Terrestrial Ecotoxicology (SANCO/3268/2001 and SANCO/10329/2002), which are currently used in the routine risk assessment of pesticides in the context of Directive 91/414/EEC replaced by Regulation (EC) No $1107 / 2009$ in June 2011. In order to develop robust and efficient environmental risk assessment procedures required by Regulation (EC) No $1107 / 2009$, it is crucial to define protection goals more precisely since risk assessors need to be able to quantify what to protect, where to protect it and over what time period.

General protection goals are defined in EU legislation, including Council Directive 91/414/EEC of 15 July, 1991 and Regulation (EC), 2009, and other legislative documents that regulate the use of other chemicals or the protection of environmental compartments in general (e.g. Directive 98/8/EC of the European Parliament and of the council of 16 February, 1998, Regulation (EC), 2006, Council Directive 92/43/EEC of 21 May, 1992 and Directive, 2000, see also Hommen et al. (2010) for a review). In Regulation (EC) No 1107/2009, a high level of protection is required (e.g. in article 1.1 and 4.3), which is expressed e.g. as "no unacceptable effects on the environment" (preambles 8, 10, 24; article 4.3) where it concerns plant protection products and "no serious risk to the environment" where it concerns treated seeds (preambles 33 and 48; article 49). However, often a "translation" into precise goals to guide the development and application of risk assessment methodology is difficult. In particular, clarifications are needed to define specific protection goals (SPGs) with respect to ecological, temporal and spatial scales; in-crop versus off-crop situations; multiple stress and uncertainties (EFSA Panel on Plant Protection Products and their Residues (PPR), 2010).

In the context of the current mandates of the PPR Panel, the framework presented here was developed. It allows the systematic development of specific protection goals for environmental risk assessment. The framework is based on the ecosystem services (ES) concept (Millennium Ecosystem Assessment, 2005) and will likely become a useful tool for the communication between risk assessors and risk managers, and between different stakeholders.

\section{The approach adopted by EFSA's PPR Panel}

This work was developed via expert discussions in the Working Group (WG) Ecotoxicological Effects, created by EFSA to support the PPR Panel in the update of the GDs for Aquatic Ecotoxicology and Terrestrial Ecotoxicology (EC (European Commission), 2002a, 2002b). This WG consisted of 19 experts, including PPR Panel members, EFSA staff and external experts. The latter were invited based on their expertise in specific scientific areas. A total of 14 meetings of the WG Ecotoxicological Effects and 4 web conferences were held between September 2008 and September 2010, supplemented by regular discussions at the PPR Panel Plenary meetings. In addition to these WG meetings, the concept presented in this manuscript was subject to wider consultation via a stakeholder workshop "Protection goals for environmental risk assessment of pesticides: What and where to protect?", held in Parma on the 15th and 16th of April, 2010. The participants of this workshop were risk assessors from European Member State authorities as well as representatives of agrochemical industry, academia, consultancy and associations. A report, written and peer-reviewed by the workshop participants, was recently published (EFSA (European Food Safety Authority), 2010). Additionally, risk managers from the European Commission and European Member States were consulted via a meeting organized in co-operation with the European Commission (Directorate General for 'Health and Consumers') in Brussels on the 11th and 12th of May 2010, back to back to a meeting of the Standing Committee on the Food Chain and Animal Health (SCFCAH). The feedback obtained from both consultations was considered and contributed to the improvement of the framework presented here.

\section{The framework to derive specific protection goals (SPGs)}

For the development of SPGs, a stepwise process was followed as explained in Figure 1 and the subsections below.

\subsection{Step 1: Decision on using the ecosystem services concept as a tool for deriving specific protection goals}

So far, the following principles and concepts have been used in the context of managing environmental risks: (i) the Precautionary Principle, (ii) the Pollution Prevention concept, (iii) the Ecological Threshold concept, (iv) the Ecological Recovery concept and (v) the Functional Redundancy concept (see Brock et al., 2006). The Precautionary Principle (EC, 2000) is based on precautionary action if the uncertainty of the risk is too great. In that case, the measures taken should be proportionate and temporary, accompanied by efforts to reduce uncertainty, and reviewed again when further information becomes available. The Pollution Prevention concept aims to prevent pollution as much as technologically and socioeconomically feasible. The Ecological Threshold concept aims always to protect sensitive populations and processes in ecosystems potentially exposed to e.g. pesticides by not accepting treatment-related ecological effects. This concept is in line with the rivet hypothesis (Ehrlich and Ehrlich, 1981) that assumes that communities are comprised of specialized species with limited capacity to compensate for each other, the loss of each additional species having an increasingly critical effect (cf. rivets in airplane wing) (Lawton, 1994). The Ecological Recovery concept presupposes that an ecosystem can absorb impacts and endure for instance a certain amount of non-persistent pesticides because of ecological recovery processes. As a consequence, exposure to e.g. pesticides should be limited to an intensity that causes reversible impacts only on sensitive populations. The Functional Redundancy concept, based on the redundancy hypothesis of Walker (1992), presupposes that for sustainable functioning of the agro-ecosystem, a decrease in biodiversity can be tolerated as long as key species and their functions are not affected beyond an unacceptable level. In communities with high functional redundancy, functional diversity is more important than taxonomic diversity (species richness) in the delivery of ecosystem services (see Munns et al., 2009). However, the insurance hypothesis of Yachi and Loreau (1999) states that taxonomic diversity within functional groups plays a crucial role in fluctuating environments by enabling ecosystems to cope with adverse effects originating from different stressors.

The five principles outlined above are in effect alternative strategies of risk assessment and risk management approaches. They may also be helpful in the context of defining protection goals in general terms. However, these 5 principles are not means for determining specifically what those protection goals should be. The latter requires a different methodology, for identifying which aspects of the environment are most valued by society, which degree of protection they deserve, or which are the maximum impacts that could be tolerated. Specific protection goals (SPGs) resulting from such a methodology could then inform the choice of strategy for risk assessment and risk management. For example, if the risks to a SPG cannot be assessed with adequate certainty, then it may be decided to take precautionary action to ensure that the SPG is not breached.

Looking for a systematic and transparent alternative methodology for defining SPG, the ecosystem services (ES) concept was identified: ecosystem services are the benefits that humans receive from ecosystems and include the production of goods (i.e. provisioning services e.g. food production), life support processes (i.e. regulating and supporting 


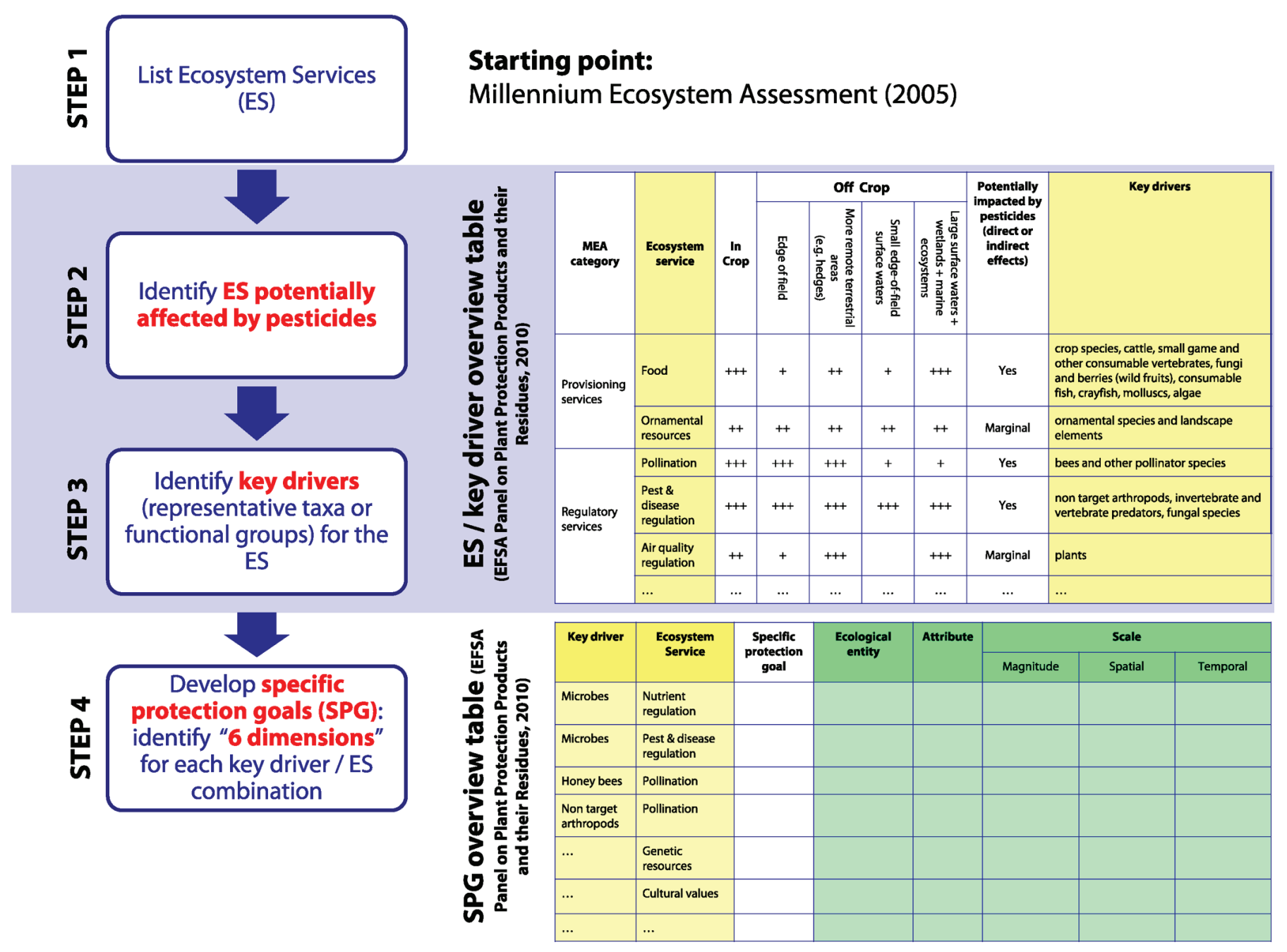

Figure 1. Steps in the process proposed (left) and their outputs (right) for developing specific protection goals (ES $=$ ecosystem services).

services) and life fulfilling conditions (i.e. cultural services) (Daily et al., 2000). This concept is currently widely recognized as a useful framework for policy makers, as stated in the Millennium Ecosystem Assessment (MEA; 2005), TEEB report (2010), and scientific literature (e.g. Vandewalle et al., 2008; Naeem et al., 2009; Perrings et al., 2010). The ES concept has been considered in European policy ( EC, 2006, 2011) and has also been discussed - and adopted for different purposes - by bodies such as the US-EPA, Environment Canada, United Nations Environment Programme and OECD (e.g. US-EPA, 2009).

Depending on the scope and application of the ecosystem services concept, several classifications and interpretations exist (e.g. Daily, 1997; De Groot et al., 2002; Millennium Ecosystem Assessment, 2005; Vandewalle et al., 2008). The framework presented in this manuscript is based on the Millennium Ecosystem Assessment (2005).

The ES concept was chosen as an overarching methodology for defining SPGs because (1) it provides a coherent conceptual framework for considering the need for protection of all types of ecosystems, (2) it can be used across environmental compartments and (3) it can be applied at a range of spatial and temporal scales. Additionally, already "formally fixed" protection goals, such as legal requirements to protect particular species, environmental compartments or geographic areas could be included in the ecosystem services concept by considering these requirements under e.g. cultural ecosystem services. A recent study comparing conservation projects that focus on promoting only biodiversity with projects that focus on promoting ecosystem services, indicated that ecosystem service projects are as effective at addressing threats to biodiversity as their biodiversity counterparts (Goldman and Tallis, 2009). This is explained by the observations that the reasons for protecting biodiversity (including for example economic, ethical, cultural, and aesthetic reasons) can be represented as ecosystem services, and that protecting ecosystem services usually requires protecting the sustainability of biological populations at the scale of the landscape. Furthermore, it has been argued that the ecosystem services concept may lead to more integrative approaches in environmental policies and could facilitate addressing these policies at different spatial and temporal scales (Van Wensem, 2009). Additionally, the ecosystem services concept can aid efficient communication between different stakeholder groups and with risk managers, in particular when defining specific protection goals: an advantage recognized by the participants of the EFSA stakeholder workshop in April 2010 (EFSA (European Food Safety Authority), 2010). Defining SPGs also draws attention to important gaps in current eco(toxico)logical knowledge that needs priority in future research.

It is clear that agricultural landscapes provide a number of ecosystem services ranging from the production of food and other raw materials, to the contribution to regulatory (e.g. water and climate regulation) and cultural (e.g. aesthetic value and recreation) services (Zhang et al., 2007; Sandhu et al., 2010). Based on the rationale introduced above, the 
list of ecosystem services as stated in the Millennium Ecosystem Assessment (MEA) (2005) was taken as a starting point for the process of deriving SPGs (Figure 1, 1st step).

\subsection{Steps 2 and 3: Identification of the relevant ecosystem services and key drivers}

The working group decided to start from the list of Ecosystem Services stated in the MEA (2005) (Figure 1, 1st step). Next, those ES that could be potentially affected by the use of pesticides were identified (Figure 1, 2nd step). This evaluation was based on expert knowledge in the working group, discriminating between in-crop and off-crop situations (terrestrial edge of the field vs. more remote natural areas, as well as small surface waters vs. large water bodies including wetlands and marine environments). Additionally, the working group made a judgment on the potential magnitude of pesticide effects. The most important ecosystem services in agricultural landscapes for both in-crop and off-crop situations which are potentially affected by pesticides are listed in Table 1. Considering the potential effects of pesticides in both in-crop and off-crop situations is important because in-crop and off-crop landscape elements may provide different ecosystem services. Additionally, taxa related to certain ecosystem services may not (always) be present in-crop but originate from other areas, e.g. pest predator species or natural pollinators that colonize crop fields from field margins or natural patches. These natural patches are, thus, important resources for the recovery of certain species when pesticide impacts occur.

Key drivers for a given ecosystem service were defined as the major taxonomic or functional groups that support the ecosystem service. Key drivers for each ES were identified and documented (Figure 1, 3rd step) and the inclusion of taxa for which data are currently requested under Directive 91/414/EEC/Regulation (EC) No 1107/2009 was checked. Initially a large number of key drivers for aquatic and terrestrial ecosystems were identified for which SPGs were derived as described below in Step 4.

\subsection{Step 4: Identification of the dimensions of the specific protection goal options for each ecosystem service and key driver combination}

Following the approach depicted in Figure 1 (4th step), specific protection goals were derived for each ecosystem service/key driver combination identified. For this purpose, specific protection goals were defined

Table 1. Overview of Ecosystem Services in agricultural landscapes for both in-crop and off-crop situations which are potentially affected by pesticides (EFSA Panel on Plant Protection Products and their Residues (PPR), 2010).

\begin{tabular}{lll}
\hline $\begin{array}{l}\text { Ecosystem service } \\
\text { category }\end{array}$ & In crop areas & Off crop areas \\
\hline Provisioning & Food & Food \\
& Fiber and fuel & Genetic resources \\
& Fresh water \\
Regulating & Pollination & Pollination \\
& Pest and disease regulation & Pest and disease regulation \\
& & Water regulation \\
& & Erosion regulation \\
& Education and inspiration & Water purification \\
Recreation and ecotourism & Education and inspiration \\
& Recreation and ecotourism \\
& Cultural heritage & Cultural heritage \\
& Primary production & Aesthetic value \\
Supporting & Photosynthesis & Photosynthesis \\
& & Habitat provision \\
& & Soil formation and \\
& & retention \\
& & Nutrient cycling \\
& & Water cycling \\
\hline
\end{tabular}

in six dimensions: (1) the entities to be protected, (2) the attributes and/ or functions of those entities, (3) the magnitude, (4) the temporal and (5) spatial scale of the effects on these attributes and/or functions that can be tolerated without impacting the general protection goal, and (6) the required degree of certainty with which the protection goal defined should be achieved (Figure 2). The list of attributes used in the scheme allows to tackle most of the cases, however, if in a specific case an additional attribute is needed, the scheme might be adapted (including e.g. reproduction). After the process of deriving SPGs for each key driver/ ecosystem service combination, those combinations leading to similar SPGs were pooled resulting into seven main categories: microbes, algae, non-target vascular plants, aquatic invertebrates, terrestrial non-target arthropods (including honey bees), terrestrial non-arthropod invertebrates, and vertebrates (covering fish, amphibians, reptiles, birds and mammals). These categories do not deviate substantially from the current taxonomic groups used in European environmental risk assessment (ERA) procedures for pesticides with the exception of microbes which are partially covered, and of amphibians and reptiles which are not covered so far. Some ecosystem services such as genetic resources (biodiversity), education and inspiration, and aesthetic value apply to all these key drivers. The level of aggregation for the key drivers differs for the various groups: there are several categories for arthropods in relation to e.g. microbes and vertebrates, which could be pooled each into one single category comprising aquatic and terrestrial organisms. This is a result of the different key driver/ecosystem service combinations that only in some cases allow the pooling, e.g. for arthropods not to the same extent as it was possible for e.g. microbes and vertebrates. Examples of the resulting SPGs are presented in Table 2.

Some of the SPG-dimensions (entity, attribute) are statements about the nature of the endpoint to be assessed, while others are statements about the maximum tolerable effect (magnitude, temporal and spatial scale) or what degree of assurance is required that these tolerable limits will not be exceeded (degree of certainty). Also, some of the dimensions are likely to be interdependent: e.g. a magnitude of effect that is acceptable over a short time scale may not be acceptable if it continues over a long time scale, or small effects on population density could be allowed at a local scale for a medium period of time, as long as on a regional scale the population is not affected.

Note that in the context of environmental risk assessment, assessing the spatio-temporal scale of the effects also requires assessing the spatio-temporal scale of the exposure. Both the exposure and effect estimates need to be expressed in terms of the same ecotoxicologically relevant concentration (ERC) (EFSA Panel on Plant Health, Plant Protection Products and their Residues, 2005; Boesten et al., 2007). Also, for any prediction scenario or model used, decisions need to be made on the "statistical population" of the landscape units to consider (e.g. only those ditches adjacent to treated fields with certain crop or all ditches in the agricultural landscape characterized by a specific crop), as well as on the percentile of this "statistical population" to be considered for selecting the estimate to be used in the risk assessment (e.g. the 90th or the 95th percentile).

The specific protection goals identified usually concern the maintenance of a diverse range of ecosystem services in the (agricultural) landscape/watershed by allowing short-term effects on local field or edge-of-field populations. For the majority of key drivers the ecological entities to be protected are (meta)populations, where a metapopulation is defined as a "population of populations" of the same species connected through immigration and emigration (Hanski and Gyllenberg, 1993). However, the selected ecological entity may also be individuals when it concerns vertebrates, species harvested for human consumption (e.g. shellfish) or species that have a protection status in national or European legislation (e.g. Habitats Directive 92/43/EEC). On the other hand, the ecological entity may also be functional groups when it concerns provisioning and supporting services by algae, some invertebrate groups and microbes. 


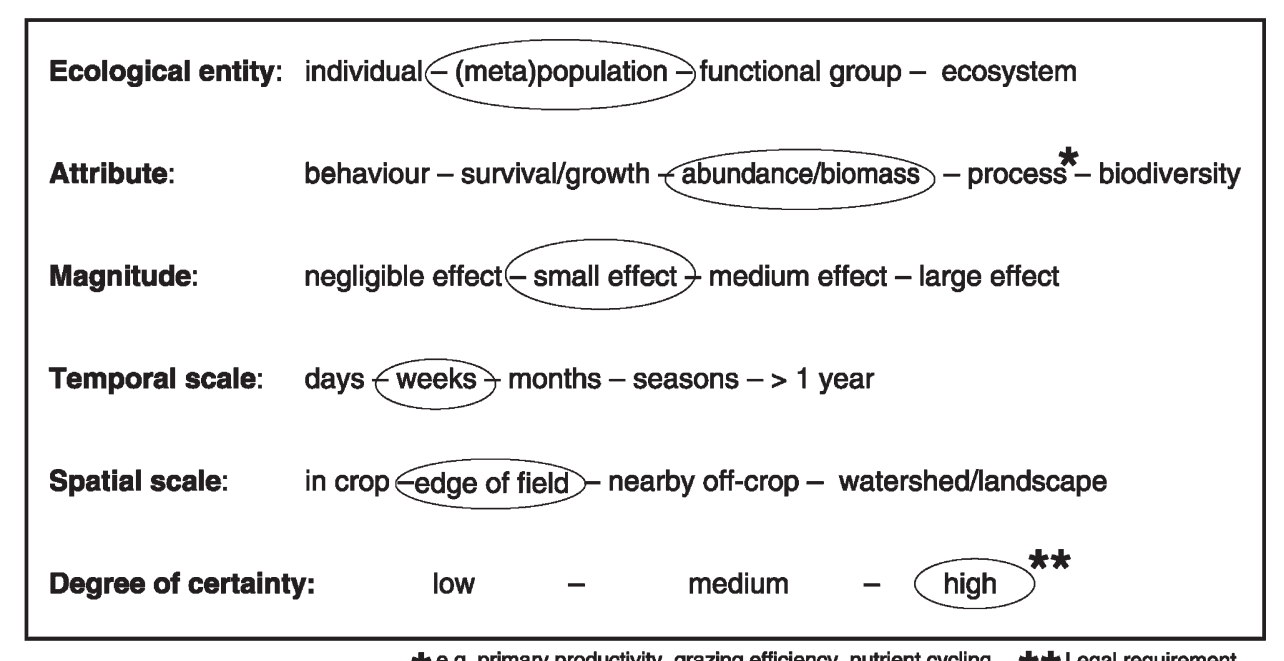

Figure 2. Example of development of a specific protection goal definition (EFSA Panel on Plant Protection Products and their Residues (PPR), 2010). For each specific protection goal option one (range of) point(s) on each dimension must be chosen, and then defined in precise enough terms to be measurable (e.g. abundance). The specific protection goal defined prevents (positive or negative) effects to the right of any of the circled points.

\section{Discussion}

For the majority of key drivers, SPGs can be defined at the level of the population or higher which is in accordance with US-EPA (2003), Delorme et al. (2005), and Hommen et al. (2010), which state that most ecological protection goals aim to preserve populations of non-target organisms rather than individuals. In these reports, however, the ecosystem services concept was not explicitly used to derive SPGs.

When the population level is adopted as the ecological entity of the SPG, effects on individual survival, reproduction and/or growth are only of concern for risk assessment if they result in impacts at the population level. For some key drivers, impacts on population size or structure resulting from pesticide use may be considered acceptable if the impacts are short-lived and local. The rate of recovery of populations from impacts depends on such factors as age-specific survival and reproduction as well as dispersal ability. Judgments about whether and to what extent impacts of pesticides at the population level are acceptable need to consider the life-history traits of the representative species for the key driver, the duration of effects caused by exposure to the pesticides and the spatial scale over which the effects occur.

Given that most of the specific protection goals relate to populations or groups of populations, development of appropriate population models for use in risk assessment is needed. Population models are already available in the literature and some of these have been used for decision making in, for example, fisheries management and conservation. Interest is recently growing for a wider application of population models for risk assessment of pesticides (e.g. Galic et al., 2010; Schmolke et al., 2010; Thorbek et al., 2010). However, challenges remain to develop a suite of models, incorporating the necessary level of ecological complexity that can be used at different tiers in the risk assessment of pesticides. These models on effects on populations should also address the appropriate linking to exposure models. Since SPGs may concern different geographical scales there is a need to also develop exposure and effect models that can be used for different geographical scales. Currently, most scenarios and tools to predict exposure and effects are developed for in-crop and edge-of-field situations only.

The key drivers for SPGs derived on the basis of the ecosystem services concept do not deviate substantially from the taxonomic groups used in the current European ERA procedures for pesticides (i.e. Regulation (EC) No 1107/2009) with the exception of microbes which are partially covered, and of amphibians and reptiles which are not covered so far. As a consequence, a critical evaluation of whether the SPGs for these taxa are indirectly met by the actions taken to achieve the SPGs for other taxonomic groups under the current ecotoxicological risk assessment guidance documents (e.g. terrestrial and aquatic vertebrates) is needed. Additionally, this framework based on the ecosystem services concept also allows to address mixture toxicity and multiple-stress caused by realistic packages of pesticides used in different crops and agricultural landscapes in the risk assessment methodology. However, to appropriately address this multiple-stress issue, relevant information for the reference tier (e.g. model ecosystems or ecosystem models simulating the crop approach and realistic pesticide use) should be made available (see e.g. Arts et al., 2006; Belden et al., 2007). Alternatively, when this type of information is not (yet) available a precautionary approach may be adopted when evaluating an individual pesticide, particularly when applied in crops with a high input of several active ingredients. It also may imply a need to define the spatial and temporal dimensions of use and hence of agro-ecological scenarios (including possible refuges), which is currently not done.

The advantage of using the ecosystem services concept is that it enables a systematic and transparent assessment of all possible SPG options and thus it may be helpful as a communication tool with risk managers, stakeholders and the public at large. The listing of all optional SPGs, which may differ for the different ecosystem services or between the areas considered, can make trade-offs and interdependencies between different ES clear allowing for an informed discussion. Societal demands for provisioning of food and other (sometimes potentially conflicting) ecosystem services, need all to be considered when identifying specific protection goals. SPGs should be defined for both in crop and off crop situations.

It needs to be kept in mind that when making choices about SPGs, in most cases some effects need to be accepted because it is not possible to optimize all ecosystem services at the same time and place. Rather it will be necessary to seek an appropriate balance between different ecosystem services, in which some will be given a degree of priority over others, keeping however the effects on the other services to a minimum. This is the point where decisions at social, political, and risk management levels are needed. Also here the ecosystem services concept can help to quantify and communicate trade-offs involved in environmental management options between different stakeholder groups involved, when defining specific protection goals. For example, the "costs" of pesticide impacts on pollination or plant biodiversity can be valued against the benefits of the pesticide use in terms of increased food production (the service being optimized in agricultural landscapes). It should be kept in mind that trade-offs among services can be expressed in different value systems 


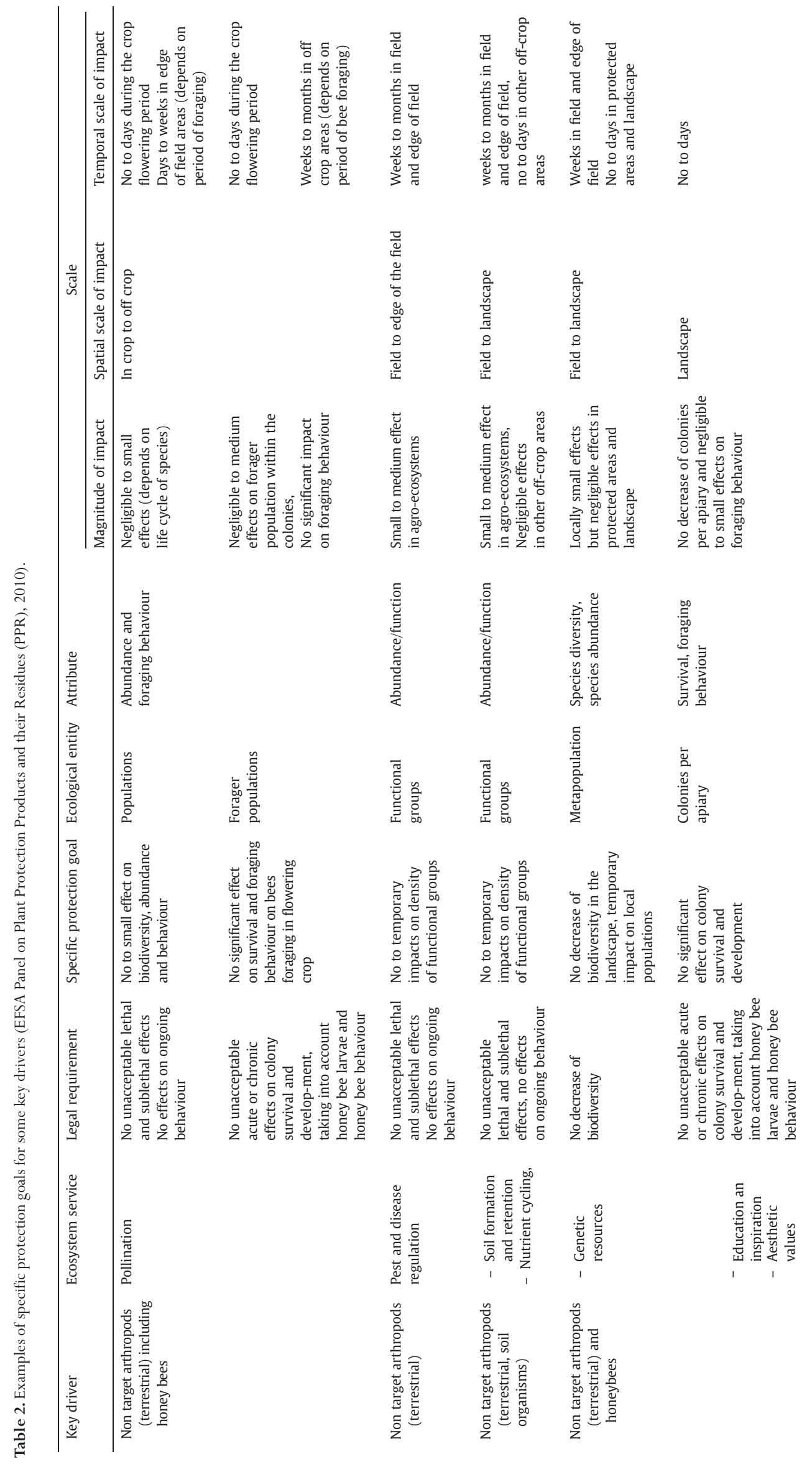




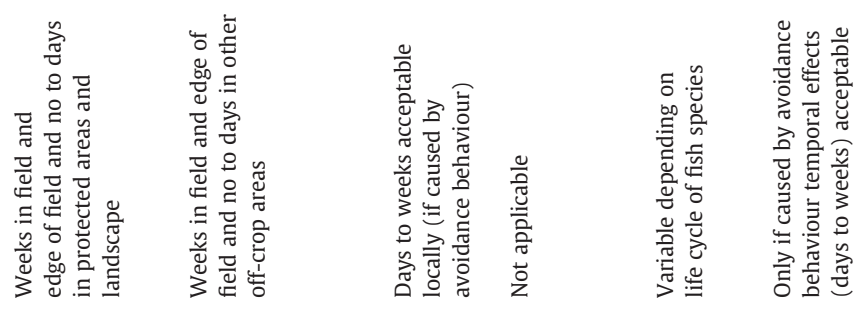

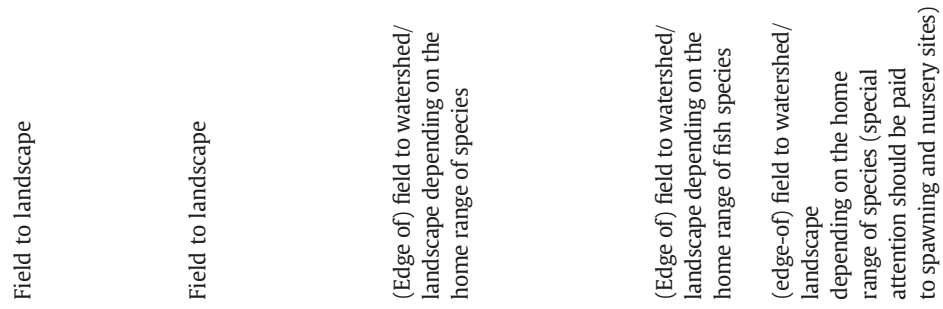

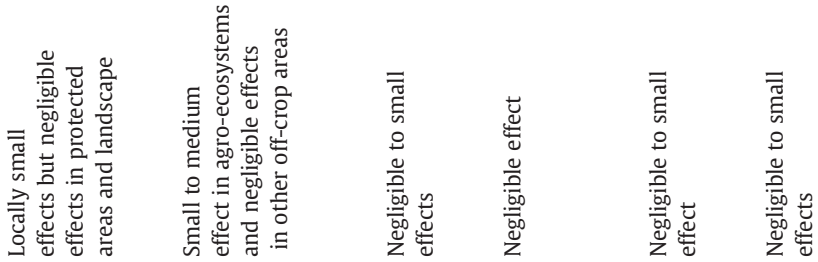

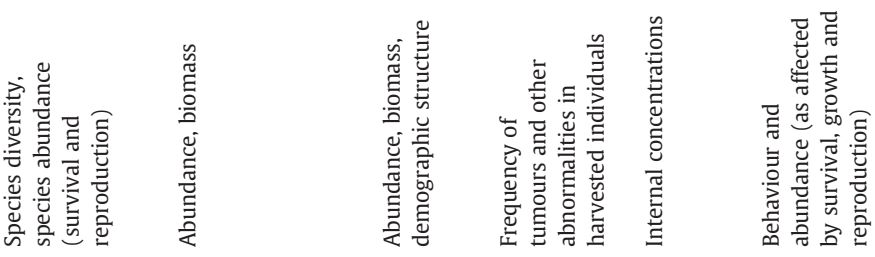

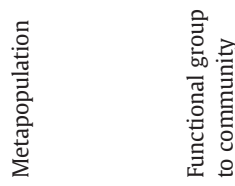

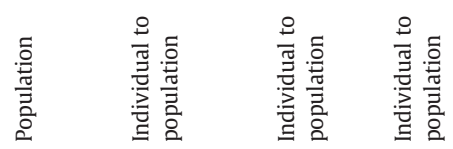

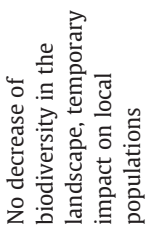

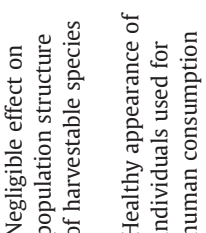

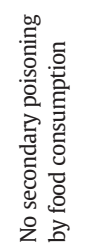
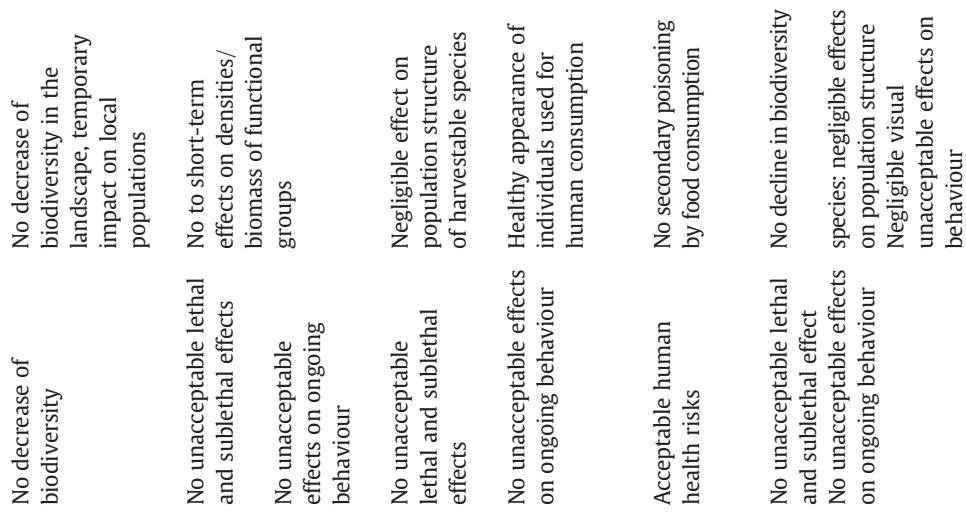

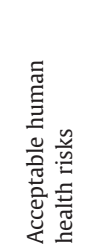

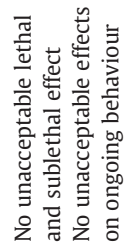

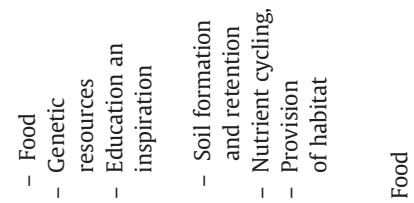
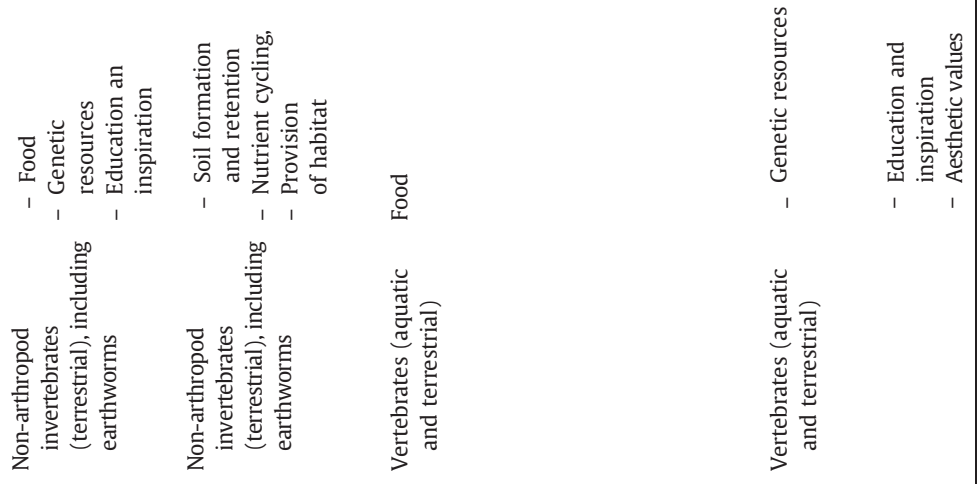
(monetary, moral values, scarcity, etc.). These features are expected to facilitate a more informed debate and ensure a more balanced use of ecosystems that ensures their long term sustainability.

It is important to recognize that final decisions on the choice of specific protection goals are the prerogative of risk managers. Final decisions on SPGs are outside the remit of EFSA as a risk assessment body. The framework presented here aims to derive specific protection goal options that can be used in this consultation dialogue.

\section{References}

Arts et al., 2006 - G. H. P. Arts, L. L. Buijse-Bogdan, J. D. M. Belgers, C. H. Van Rhenen-Kersten, R. P. A. Van Wijngaarden, and I. Roessink, et al. Ecological impact in ditch mesocosms of simulated spray drift from a crop protection program for potatoes. Integr Environ Assess Manag, 2 (2006), pp. 105-125.

Belden et al., 2007 • J. B. Belden, R. S. Gilliom, J. D. Martin, and M. J. Lydy, Relative toxicity and occurrence patterns of pesticide mixtures in streams draining agricultural watersheds dominated by corn and soybean production. Integr Environ Assess Manag, 3 (2007), pp. 90-100.

Boesten et al., 2007 • J. J. T. I. Boesten, H. Köpp, P. I. Adriaanse, T. C. M. Brock, and V. E. Forbes, Conceptual model for improving the link between exposure and effects in the aquatic risk assessment of pesticides. Ecotoxicol Environ Saf, 66 (2007), pp. 291-308.

Brock et al., 2006 • T. C. M. Brock, G. H. P. Arts, L. Maltby, and P. J. Van den Brink, Aquatic Risks of pesticides, ecological protection goals, and common aims in European Union legislation. Integr Environ Assess Manag, 2 (2006), pp. e20-e46.

Council Directive 91/414/EEC of 15 July, 1991 - Council Directive 91/414/ EEC of 15 July 1991 concerning the placing of plant protection products on the market. OJ L 230, 19. 8. 1991, p. 1-32.

Council Directive 92/43/EEC of 21 May, 1992 • Council Directive 92/43/EEC of 21 May 1992 on the conservation of natural habitats and of wild fauna and flora. OJ L 206, 22. 07. 1992 p. 7-50.

Daily, 1997 - G. C. Daily, Nature's services, societal dependence on natural ecosystems, Island Press, Washington, USA (1997), 392 pp.

Daily et al., 2000 • G. C. Daily, T. Söderqvist, S. Anivar, K. Arrow, P. Dasgupta, and P. R. Ehrlich, et al. The value of nature and the nature of value. Science, 289 (2000), pp. 395-396.

De Groot et al., 2002 • R. S. De Groot, M. A. Wilson, and R. M. J. Boumans, A typology for the classification, description and valuation of ecosystem functions, goods and services. Ecol Econ, 41 (2002), pp. 393-408.

Delorme et al., 2005 • P. Delorme, D. François, C. Hart, V. Hodge, G. Kaminski, and C. Kriz et al., Final report for the PMRA workshop: assessment endpoints for environmental protection, Environmental Assessment Division, Pest Management Regulatory Agency, Health Canada, Ottawa, ON, Canada (2005) 63 pp.

Directive, 2000 - Directive 2000/60/EC of the European parliament and of the Council of 23 October 2000 establishing a framework for Community action in the field of water policy. OJ L 327, 22. 12. 2000, pp. 1-73.

Directive 98/8/EC of the European Parliament and of the council of 16 February, 1998 - Directive 98/8/EC of the European Parliament and of the council of 16 February 1998 concerning the placing of biocidal products on the market. OJ L 123/1, 24. 4. 1998, p. 1-63.

EC (European Commission), 2000 • EC (European Commission), 2000. Communication from the Commission on the Precautionary Principle. Brussels. No. COM (200) 1, 29 pp.

EC (European Commission), 2002a - EC (European Commission) Guidance document on aquatic ecotoxicology in the context of the Directive 91/414/EEC (SANCO/3268/2001) rev. 4 final, 17. 11. 2002 (2002), pp. 1-62.

EC (European Commission), 2002b - EC (European Commission) Guidance document on terrestrial ecotoxicology under Council Directive 91/414/EEC (SANCO/10329/2002) rev. 2 final, 17. 10. 2002 (2002), pp. 1-39.

EC (European Commission), 2006 • EC (European Commission) Communication from the European Commission. Halting the loss of biodiversity by 2010 - and beyond. Sustaining ecosystem services for human well-being. COM(2006) 216 final, 22. 5. 2006 (2006), pp. 1-15.

EC (European Commission), 2011 • EC (European Commission) Communication from the Commission: our life insurance, our natural capital: an EU biodiversity strategy to 2020. $\operatorname{COM(2011)~} 244$ final, 3. 5. 2011 (2011), p. 17.

EFSA (European Food Safety Authority), 2010 • EFSA (European Food Safety Authority), Report on the PPR stakeholder workshop protection goals for environmental risk assessment of pesticides: what and where to protect?, EFSA J, 87 (2010), p. 167246 pp.

EFSA Panel on Plant Health, Plant Protection Products and their Residues, 2005 - EFSA Panel on Plant Health, Plant Protection Products and their Residues, Opinion of the scientific panel on plant health, plant protection products and their residues on a request from EFSA related to the evaluation of dimoxystrobin. EFSA J, 178 (2005), pp. 1-45.

EFSA Panel on Plant Protection Products and their Residues (PPR), 2010 •
EFSA Panel on Plant Protection Products and their Residues (PPR), Scientific opinion on the development of specific protection goal options for environmental risk assessment of pesticides, in particular in relation to the revision of the Guidance Documents on Aquatic and Terrestrial Ecotoxicology (SANCO/3268/2001 and SANCO/10329/2002), EFSA J, 810 (2010), p. 1821 [55 pp. ].

Ehrlich and Ehrlich, 1981 • P. R. Ehrlich and A. H. Ehrlich, Extinction: the causes and consequences of the disappearance of species, Random House, New York (1981), 305 pp.

Galic et al., 2010 • N. Galic, U. Hommen, J. M. H. Baveco, and P. J. van den Brink, Potential application of population models in the European ecological risk assessment of chemicals ii: review of models and their potential to address environmental protection aims. Integr Environ Assess Manag, 6 (2010), pp. 338-360.

Goldman and Tallis, 2009 • R. L. Goldman and H. Tallis, A critical evaluation of ecosystem services as a tool in conservation projects: the possible perils, the promises, and the partnerships. Ann NY Acad Sci, 1162 (2009), pp. 63-78.

Hanski and Gyllenberg, 1993 - I. Hanski and M. Gyllenberg, Two general metapopulation models and the core-satellite species hypothesis. Am Nat, 132 (1993), pp. 360-382.

Hommen et al., 2010 • U. Hommen, J. M. Baveco, N. Galic, and P. Van den Brink, Potential application of ecological models in the European environmental risk assessment of chemicals: I. Review of protection goals in EU directives. Integr Environ Assess Manag, 6 (2010), pp. 325-337.

Lawton, 1994 • J. H. Lawton, What do species do in ecosystems?. Oikos, 71 (1994), pp. $367-374$.

Millennium Ecosystem Assessment (MEA), 2005 • Millennium Ecosystem Assessment (MEA), Ecosystems and human well-being: synthesis, Island Press, Washington, DC (2005), 160 pp.

Munns et al., 2009 •W. R. Munns, R. C. Helm, W. J. Adams, W. H. Clements, M. A. Cramer, and M. Curry, et al. Translating ecological risks to ecosystem service loss. Integr Environ Assess Manag, 5 (2009), pp. 500-514.

Naeem et al., 2009 • S. Naeem, D. E. Bunker, A. Hector, M. Loreau, and C. Perrings, Biodiversity, ecosystem functioning and human wellbeing: an ecological and economic perspective, Oxford University Press, Oxford, UK (2009), 368 pp.

Perrings et al., 2010 - C. Perrings, S. Naeem, F. Ahrestani, D. E. Bunker, P. Burkill, and G. Canziani, et al. Ecosystem services for 2010. Science, 330 (2010), pp. 323-324.

Regulation (EC), 2006 • Regulation (EC) No 1907/2006 of the European Parliament and of the Council of 18 December 2006 concerning the Registration, Evaluation, Authorisation and Restriction of Chemicals (REACH), establishing a European Chemicals Agency, amending Directive 1999/45/EC and repealing Council Regulation (EEC) No 793/93 and Commission Regulation (EC) No 1488/94 as well as Council Directive 76/769/EEC and Commission Directives 91/155/EEC, 93/67/EEC, 93/105/EC and 2000/21/EC. OJ 396/1, 30. 12. 2006, p. 1-849.

Regulation (EC), 2009 • Regulation (EC) No 1107/2009 of the European Parliament and of the Council of 21 October 2009 concerning the placing of plant protection products on the market and repealing Council Directives 79/117/EEC and 91/414/EEC. OJ L 309/1, 24. 11. 2009, p. 1-50.

Sandhu et al., 2010 • H. S. Sandhu, S. D. Wratten, and R. Cullen, Organic agriculture and ecosystem services. Environ Sci Policy, 13 (2010), pp. 1-7.

Schmolke et al., 2010 • A. Schmolke, P. Thorbek, P. Chapman, and V. Grimm, Ecological models and pesticide risk assessment: current modeling practice. Environ Toxicol Chem, 29 (2010), pp. 1006-1012.

TEEB, 2010 TEEB, The Economics of ecosystems and biodiversity: mainstreaming the econom ics of nature: a synthesis of the approach, conclusions and recommendations of TEEB (2010).

Thorbek et al., $2010 \bullet$ P. Thorbek, V. Forbes, F. Heimbach, U. Hommen, H. H. Thulke, P. van den Brink, Editors et al., Ecological models for regulatory risk assessments of pesticides: developing a strategy for the future, Society of Environmental and Chemistry (SETAC) and CRC Press (2010).

US-EPA, 2003 • US-EPA, Generic ecological assessment endpoints (GEAEs) for ecological risk assessment, United States Environmental Protection Agency, risk assessment forum, Washington, DC, USA, report EPA / 630/P-02/004F (2003) 59 pp.

US-EPA, 2009 - US-EPA, Valuing the protection of ecological services, $A$ report of the RPA science advisory board, United States Environmental Protection Agency, report code EPASAB-09-012 (2009) $121 \mathrm{pp}$.

Van Wensem, 2009 J J Van Wensem, Ecosystem services: a new approach in ecological risk assessment, http://www.tcbodem.nl/files/Ecosystem $\% 20$ Services $\% 20$ \&\%20RA\%202009.pdf (2009) (May 12, 2011).

Vandewalle et al., $2008 \cdot$ M. Vandewalle, M. T. Sykes, P. A. Harrison, G. W. Luck, P. Berry, and R. Bugter, et al. Review paper on concepts of dynamic ecosystems and their services, Available online from http://www.rubicode.net/rubicode/RUBICODE Review on Ecosystem Services.pdf (2008) (May 12, 2011).

Walker, 1992 B. H. Walker, Biodiversity and ecological redundancy. Conserv Biol, 6 (1992), pp. 18-24.

Yachi and Loreau, 1999 - S. Yachi and M. Loreau, Biodiversity and ecosystem productivity in a fluctuating environment: the insurance hypothesis. PNAS, 96 (1999), pp. 1463-1468.

Zhang et al., 2007 - W. Zhang, T. H. Ricketts, C. Kremen, K. Carney, and S. M. Swinton, Ecosystem services and dis-services to agriculture. Ecol Econ, 64 (2007), pp. 253-260. 